\title{
Improving the understanding of structural design module through a group coursework
}

\begin{abstract}
Structural engineering is a field of engineering that ensures that the structure can be constructed and is durable and stable, which help to meet the need for a more sustainable world. This paper focused on improving student understanding of structural engineering (concrete and steel). A questionnaire was given to the students to see their responses regarding the coursework, the questionnaire contains 10 questions and most of the questions had a scale of 1-5, with being 1- strongly agree 2- agree 3- Neutral, 4- Disagree, and 5- Strongly Disagree. The conclusion drawn from the results are that student understanding can be improved significantly through a coursework. The students have learned a different type of learning environment, time management, communication skills, and meeting deadlines.
\end{abstract}

Keywords: structural design, steel, concrete, activity led learning
Volume 2 Issue 4 - 2017

\author{
Michael Gerges,' Mohammad Mayouf,' Steve \\ Austin $^{3}$ \\ 'School of Civil and Building, Loughborough University, UK \\ ${ }^{2} \mathrm{School}$ of Engineering and the Built Environment, Birmingham \\ City University, UK \\ ${ }^{3}$ Civil and Structural Engineering, Coventry University, UK
}

Correspondence: Michael Gerges, School of Civil and Building, Loughborough University, UK,

Email michaelzahergerges@gmail.com

Received: February 24, 2017 | Published: April 20, 2017

\section{Introduction}

Structure engineering is the science of designing and creating a frame or skeleton that can resists the applied load. ${ }^{1}$ As a structural engineer, we are concerned with two main things 1) safe from falling down - strength and 2) safe from falling over - stability. Students think of structural analysis to be highly relevant to practice, but in the same time difficult to understand and not of outstanding intrinsic interest. ${ }^{2}$

The structural team (at one of the UK universities) aim is to deliver all structural analysis theory relevant to the needs of industry. We make sure the students are to a standard to face the industry's challenges when they graduate. Saidiani ${ }^{3}$ states that Activity Led Learning in forms of practical work (lab-based, group work, computer modeling and investigate individual mini projects) is found by students to be the favorite way of learning. In particular, group work makes the student learn more than in lectures and tutorials. Johnson et al. ${ }^{2}$ states that lectures are not rated highly in terms of student motivation and that student must understand that they are learning not too pass a module, but learning for a career in this discipline.

Out of 143 students in Structural Design second year there was 36 students who have failed and had to reset the exam. Surprisingly, out of the 36, 27 are International students. Some argue that language is a barrier, but some of the student's English was very good and have received more than 6.0 in the IELTS. We had to ask the students where they think the problem was: 1) The module was ok in the first couple of weeks, then it was hard to keep up since there is a new topic taught in every lecture 2) The pace of the lecture was to quick, and if I do not attend the tutorial then I don't understand the topic. 3) I tend to learn better when there is a link between theory and practical, and I didn't see any practical in the module. 4) I didn't find the tools that could help me understand the module.

The main aim of this paper is to improve the pass rate and the understanding of $2^{\text {nd }}$ year Civil Engineering of the structural design: steel and concrete.

\section{Objectives}

I. Get students to be engaged in a more practical work other than sitting in a lecture and doing equations.
II. Students to design an extension building for a headquarter.

III. Focus on students understanding of the module material rather than passing an exam.

IV. Improve student learning environment in structural design of steel and concrete.

V. Feedback given to students by experienced academics and industrial engineers based on their design.

\section{Solution}

a. To give a design project for an extension for an headquarter building.

b. Students form themselves of group of 5-7 members.

c. The student starts to put sketches and a plan how to design the project.

d. Presenting the final presentation of the poster at the end of March to experienced industrial Professionals and Academics.

\section{Phase I (Preliminary options study and report writing)}

a. Load transfer mechanism, framing and stability functions, notes on construction methodology of each proposal, cost, aesthetics, sustainability, and sand technical innovation

b. Site investigation report for foundation

\section{Phase 2A (Detailed design, tender drawings and construction)}

a. Presentation to the Client (Experienced Industrial and Academic Professionals) of the extension of the head quarter and explain what they have done and why chose that option.

\section{Phase2B (Presentation)}

I. Prepare sufficient superstructure calculations to establish the form and size of all the principal structural elements (beams, columns, trusses, foundations).

II. A3 drawing should include plan and elevations. 
III. Annotated sketches of the construction sequences.

\section{Methodology}

According to Longhofer et al., ${ }^{4}$ qualitative research method is able to understand the "social world based on small scale sample". It is also used interactive ways in order to collect data such as questionnaires; that allows further exploration of the depth of the issues and ideas, ${ }^{4}$ and supporting the objectives of the research. In addition the participants will also be able to offer their ideas and thoughts in an interactive manner. ${ }^{5}$ Therefore it was decided to use a qualitative approach rather than quantitative approach.

In this paper, a questionnaire was given to the students after the presentation to see the results of the coursework on them. 151 questionnaires were returned from original 157 sent out. The questionnaire only consisted of 10 questions and gave a clear identification to the researcher what were the advantages and disadvantages of the coursework. Most of the questions had a scale of 1-5, with 1- being strongly agree, 2- agree, 3- Neutral, 4- Disagree, 5- Strongly Disagree. ${ }^{6}$

\section{Results and analysis}

The results that placed below reflect the responses of the presented questions in the questionnaire. As shown in Table 1, the percentage of the project marks was divided into 5 categories. It is evident that the highest number of groups received marks was for the percentages of $70 \%-79 \%$. While the lowest number of groups among them was for the percentage of $40 \%-49 \%$. Moreover, only 5 groups received a mark below $60 \%$, compared to 20 groups received a mark above $60 \%$. From the pie chart above, the majority of respondents (33\%) neutral that the coursework improved their understanding of the module, followed by $23 \%$ strongly agree and $19 \%$ agree, while $16 \%$ of the student disagree and $9 \%$ strongly disagree with the statement. Moving on to Figure 1 , the pie chart shows the reflection of the responses of question two as presented in the questionnaire which states, 'Did this Coursework Help you Prepare for the Exam'. As shown in Figure 2, the pie chart results have given very similar proportions to the first question, with (31\%) neutral compared to $33 \%$ for the majority of the respondents, and $42 \%$ in the first pie chart compared to $46 \%$ for the second pie chart for the student who strongly agree and agree with the statement, while $25 \%$ of the student in Figure 1 strongly disagree and disagree with the question compared to $23 \%$ in Figure 2.

Table I The number of groups received marks

\begin{tabular}{ll}
\hline $\begin{array}{l}\text { Percentage of } \\
\text { project marks }\end{array}$ & $\begin{array}{l}\text { Number of groups } \\
\text { received marks }\end{array}$ \\
\hline $40 \%-49 \%$ & 1 \\
$50 \%-59 \%$ & 4 \\
$60 \%-69 \%$ & 6 \\
$70 \%-79 \%$ & 11 \\
$80-89 \%$ & 3 \\
\hline
\end{tabular}

According to the responses in Figure 1-3, most of the students selected strongly agree and agree with the statement, which indicates that coursework improved their ability to understand the module and helped them to prepare for the exams. Question 3 in the questioner states 'Was the Coursework Brief Clear and Have you Got Help Required from Stuff'. According to the chart, $40 \%$ was the largest portion of the chart that strongly agreed with the question and did see that the coursework brief clear and they have got the help required from the stuff, while the smallest portion ( $8 \%$ ) of the diagram strongly disagreed with the statement.

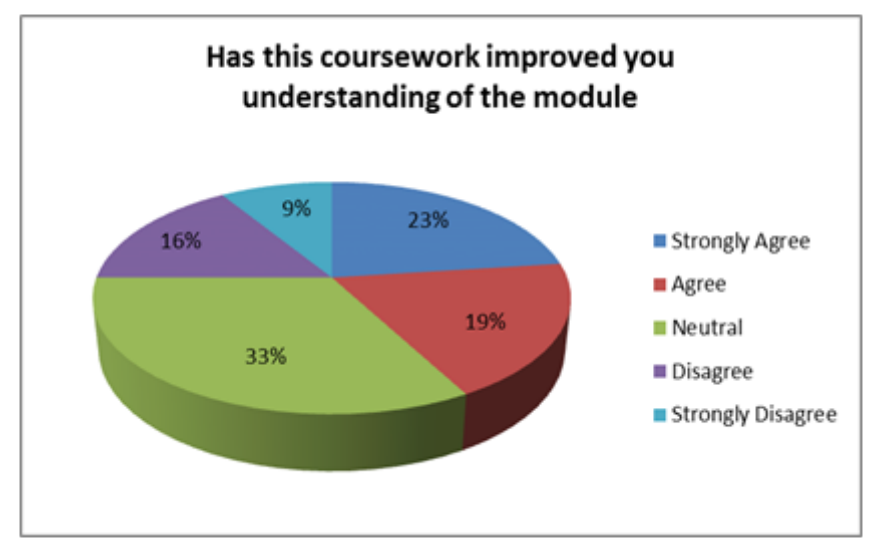

Figure I Has this coursework improved you understanding of the module.

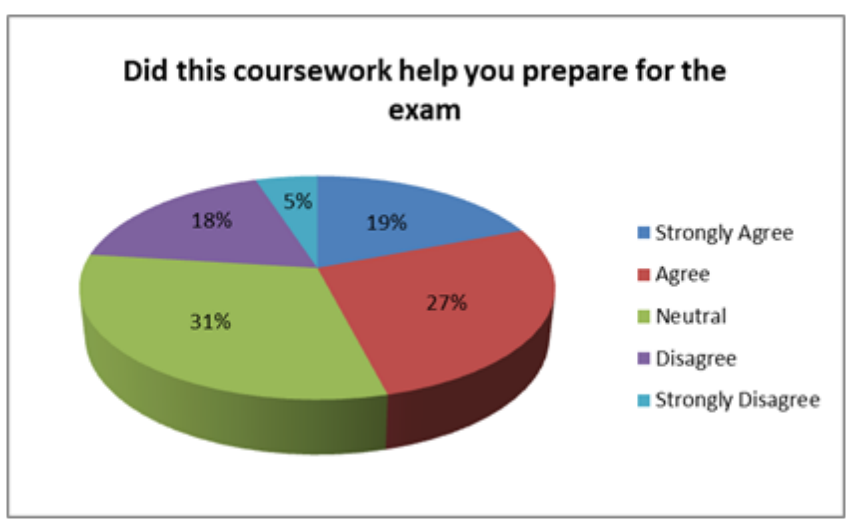

Figure 2 Did this coursework help you prepare for the exam.

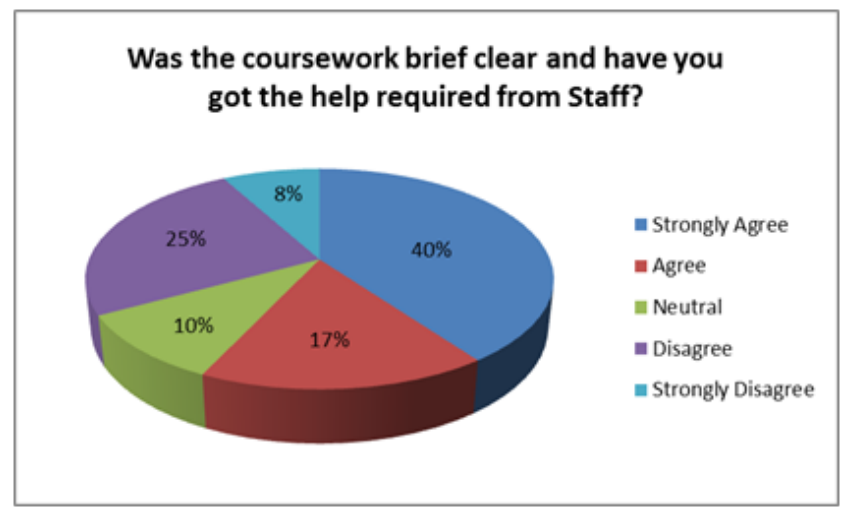

Figure 3 Was the coursework brief clear and have you got the help required from stuff.

Figure 4 shows the percentage of the group marks out of the 25 groups, it's evident from the pie chart that the majority of the groups with $44 \%$ got marks within the range of $70 \%-79 \%$, followed by $24 \%$ got marks from $60-69$. In addition a very similar proportion with $16 \%$ and $12 \%$ got marks within $50 \%-59 \%$ and $80 \%-89 \%$ respectively, while only $4 \%$ of the groups got marks below $50 \%$. The following pie chart illustrates student responses to the fourth question 'Do you Prefer Work or Individual Work'. 


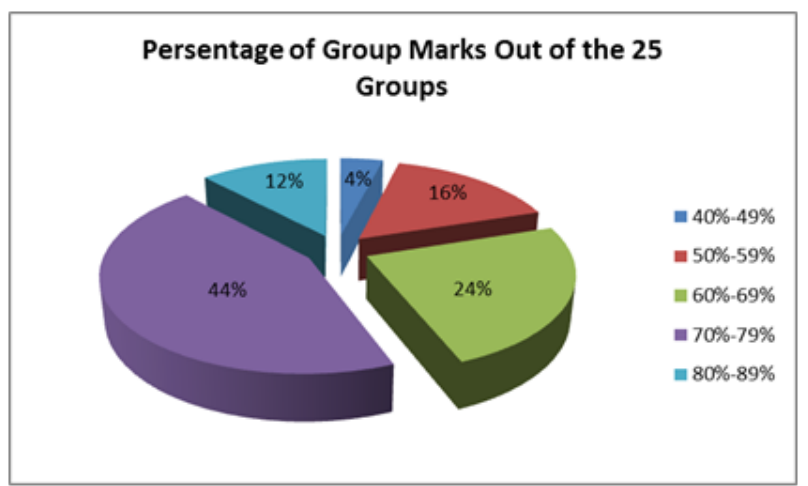

Figure 4 Percentage of group marks out of the 25 Groups.

As shown in Figure 5, the pie chart illustrates that the majority of the students with more than three quarters (79\%) prefer the group work, whilst less than a quarter $(21 \%)$ prefer the individual work. The pie chart below represents question five which examines the question. 'Would you recommended that this coursework to be a part of the module for next year'. The pie chart above presents the responses of the students who has two options, yes and no. The majority selected yes with $93 \%$ whilst the remainder with $7 \%$ selected no. This indicates that the students benefited from the coursework, that's why they recommend this coursework to be a part of the module for next year Figure 6.

\section{Do you prefer group work or individual work?}

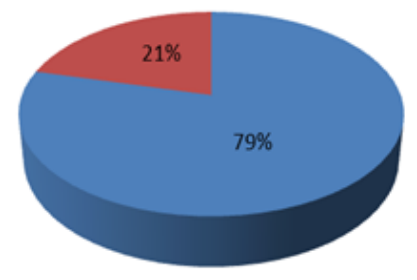

aroup Work

andividual Work

Figure $\mathbf{5}$ Do you prefer group work or individual work.

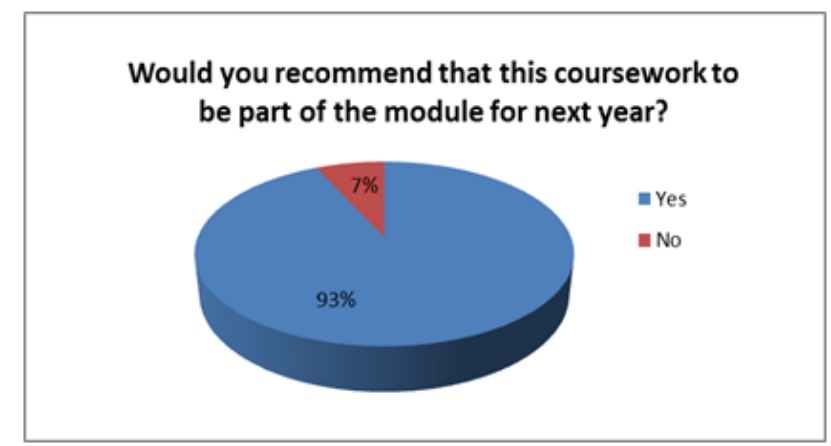

Figure 6 Would you recommend that this coursework to be part of the module for next year.

\section{Feedback from staff and professionals}

I think the challenges students faced during this project made them understand how to work in a busy environment. They have done a very good effort to present all their knowledge. Student have developed many skills and knowledge in team work, communication skills, and the main thing in structural engineering where they have shown they can design a structural building from A-Z . To be honest, it was a pleasure to be a judge in this project, I was really amazed by the explanation the students provided regarding their designs, and what have they done. They have shown a clear understanding of their design, and explained it very well.

\section{Student's feedback}

I really like the coursework, since it was challenging and we as a group had to go through Eurocode and Library books to be able to complete the coursework.

Phase 2 was more useful to me than Phase 1, because by calculating all the beams and columns for the steel and concrete. I have revised for my exam, and understood things better during the process of the coursework.

It was a good experience working with classmates I didn't know before this coursework, they have added to my skills.

This coursework has made me understand what type of work I will be doing when I graduate, and how to complete many tasks at a certain deadline.

\section{Conclusion and recommendations}

A $30 \%$ coursework project improved the overall understanding of students to the module. With a pass rate of $88 \%(138 / 157)$, international students have managed to express themselves among others member of the group where there was always a problem that international students engaging in class, activities, lectures, coursework, and discussions. The project provided a different type of learning environment; they had to research and attend workshops to know how to complete the project to the best standard possible. Time management, communication skills, and meeting deadlines were also key improvement the students have gained through the project.

It can clearly be stated that based on the results obtained from the students and Professionals/Academic feedback that this project was a complete successful in meeting its Aims/Objectives. The project has been set to be part of the module for the next coming years. Other academics have also thought that it was exciting and interesting, where they will have something similar in their modules.

\section{Acknowledgements}

None.

\section{Conflict of interest}

The author declares no conflict of interest.

\section{References}

1. Roycroft J. Structural Engineering for beginners. 2013.

2. Johnson D, May Ian. The Teaching of Structural Analysis. UK: The Ove Arup Foundation; 2008. 30 p.

3. Saidani Messaoud. Making Structural analysis fun to learn; challenges and opportunities. National HE stem program; 2012. 6 p.

4. Longhofer J, Floersch L, Hoy J. Qualitative methods for practice research. USA: Oxford University Press; 2013. 216 p.

5. Creswell JW. Research design: qualitative \& quantitative approaches. 2nd ed. India: Sage Publications; 2009. 26 p.

6. Pedron Claudia. An Innovative tool for teaching structural analysis and design. 2006. 140 p. 